shared success stories on the theme of \#OceanOptimism, and Mike Barry from UK retailer Marks \& Spencer gave an unfamiliar perspective from business.

For this young conservationist, a highlight was the insightful evening lecture from Tom Brooks, IUCN, Switzerland, entitled simply Does conservation work? The answer was a robust and resounding yes, we simply need more of it: heartening words from someone at the centre of global conservation efforts.

A series of workshops (a feature that sets SCCS apart from many conferences) gave delegates a chance to experience primers on broad topics such as statistics, genetics and experimental design or hear from experts such as Oryx's editor Martin Fisher, and Bill Sutherland, who leads Conservation Evidence. The body of the conference consisted of 32 talks from students who had come from as far afield as Iran, Madagascar and Cambodia (and as close as Cambridge). Most other delegates brought posters, which generated engaging discussion during the coffee breaks and lunch sessions.

Attending conferences, presenting research, and networking are important parts of our development as scientists. But SCCS goes further, providing an opportunity for early-career conservationists to immerse themselves among like-minded people from all around the world-an opportunity not to miss.

The next Cambridge SCCS will take place during 28-30 March 2017. Updates will be posted on the conference website (http://www.sccs-cam.org). There are now sister SCCS series in Australia, China, Hungary, India and the USA. Dates and application details are on the SCCS Cambridge website, http://www.sccs-cam.org.

JAMES BoRRELL Schools of Biological and Chemical Sciences, Queen Mary, University of London, London, UK

E-mail j.s.borrell@qmul.ac.uk

\section{7th International Conservation Workshop for Arabia's Biodiversity}

The 17th Annual International Conservation Workshop for Arabia's Biodiversity was held at the Breeding Centre for Endangered Arabian Wildlife in Sharjah, United Arab Emirates, on 8-11 February 2016. This regional forum brought together over 150 participants representing UAE, Jordan, Saudi Arabia, Bahrain, Kuwait, Yemen, Oman, Qatar and Iraq, as well as from the UK, USA, South Africa, Italy and New Zealand. The Sharjah workshops are hosted by the Environment and Protected Areas Authority of the Government of Sharjah, under the patronage of H.H. Sheikh Dr Sultan bin Mohammed al Qasimi, Member of the Supreme Council and Ruler of Sharjah.

The 17th Workshop had four themes. A species assessment theme conducted a review of the distribution and conservation status of all mammals in the Arabian region. The protected areas and planning theme worked in conjunction with mammal assessments to compile an up-to-date register of all biodiversity of protected areas in the region, to facilitate an evaluation of current mammal protection and future needs. The veterinary theme looked at the issue of wild ungulate disease diagnosis and management, with an emphasis on tuberculosis, and was expanded to consider the complications associated with mass game capture and the use of short- and long-acting tranquillizers.

Two working groups conducted a regional Red List assessment of all species of terrestrial mammals in the Arabian region, the Arabian Peninsula and Syria and Iraq. Over 160 species were assessed. In association with this assessment, a comprehensive compilation of summary data on biodiversity in protected areas was completed. Over 150 protected areas were identified, and the boundaries of key areas were mapped to facilitate a gap analysis of current and future conservation needs for threatened mammal taxa. A third working group reviewed the status and distribution of the 22 species of marine mammals in the Arabian region, the first time this exercise has been carried out.

The lack of species-specific diagnostic tests for tuberculosis, diagnostic capacity in the region, and transparency make this a very difficult disease to control. This year there was a combined workshop session looking at threats to the mammals of the region, acknowledging that veterinarians and conservation managers are part of the One Health concept that looks at the interface between humans, animals and the environment, including the diseases threatening livestock, free-roaming wildlife, and humans.

PHILIP SEDDON Department of Zoology, University of Otago, Dunedin, New Zealand.E-mail philip.seddon@otago.ac.nz

MIKE KNIGHT South African National Parks, \& Centre for African Conservation Ecology, Nelson Mandela Metropolitan University, Port Elizabeth, South Africa

GeRHARD STEENKAMP Department of Companion Animal Clinical Studies, Faculty of Veterinary Science, University of Pretoria, Ondeserspoort, South Africa

Craig Hilton-Taylor IUCN Red List Unit, The David Attenborough Building, Pembroke Street, Cambridge, UK

DAVID MaLlon Manchester Metropolitan University, UK, \& IUCN/Species Survival Commission Conservation Planning Sub-Committee

\section{The Whitley Awards 2016}

The annual Whitley Awards Ceremony was held on 27 April 2016 at the Royal Geographical Society in London. The 